\title{
Optimization of Photoelastic Properties and Stress Relief of Small-Sized Polycarbonate Disks for Granular Material Photoelastic Tests
}

\author{
M. X. Hou, ${ }^{a, b, 1}$ M. X. Tang, ${ }^{a}$ and H. S. Hu \\ a South China University of Technology, Guangzhou, China \\ ${ }^{\mathrm{b}}$ Guangzhou Institute of Building Science, Guangzhou, China \\ ${ }^{1}$ worldwudiming@gmail.com
}

УДК 539.4

\section{Оптимизация фотоупругих свойств и релаксации остаточных напряжений в малых поликарбонатных дисках для фотоупругих испытаний гранули- рованных материалов}

\author{
М. К. Хоу ${ }^{a, 0}$, М. К. Танг ${ }^{a}$, Х. С. Хy \\ ${ }^{\text {a }}$ Южнокитайский технологический университет, Гуанджоу, Китай \\ ${ }^{\sigma}$ Строительный институт Гуанджоу, Китай
}

Поликарбонат является оптимальным фотоупругим материалом для проведения механических испьтаний методом фотоупругости. Для получения небольших частии поликарбоната, применяемых при фотоупругих испытаниях гранулированного материала, из поликарбонатной пластины, предварительно подвергнутой отжигу для релаксации остаточных напряжений, вырезаются прозрачные циилиндрические диски малого диаметра. Режимы резки и отжсиа оптимизировань в результате анализа механических и фотоупругих свойств поликарбонатных дисков разного диаметра и постоянной высоты (5 мм). Анализ фотоупругих характеристик напряженно-деформированного состояния дисков и изохром подтвердил высокую эффективность предлагаемых режимов обработки и отжига для данного материала.

Ключевые слова: поликарбонат, гранулированный материал, метод фотоупругости, отжиг, релаксация остаточных напряжений.

Introduction. Polycarbonate material (PCM) is the general name for thermoplastic, amorphous polymers. Being an amorphous and transparent engineering plastic, it has favorable comprehensive properties because of its unique chemical molecular structure, such as high tensile strength, good impact, heat, and creep resistances, nontoxic environmentfriendly performance, and dimensional stability. Hence, polycarbonate products have been incorporated into a variety of domains: electronic devices, building materials, medicine, mechanical engineering, household products, and many other applications. Furthermore, they also find increasing demand in automobile, aircraft and spacecraft industries [1-6]. Insofar as polycarbonate has high optical sensitivity, time edge effect, high transparency, low optical creep, and good mechanical processing properties, it has been applied to photoelastic tests immediately after its appearance in 1962.

This photoelasticity method was advanced nearly two hundred years ago and has been widely used for stressed state estimation of elastic materials with unique stress-strain dependence. However, in contrast to elastic materials, the internal stresses and strains in granular materials have no unique interrelation, which can be used to determine the stress increment in a region with known deformation. The behavior of packed particles in the 
above materials strongly depends on the stress history and path, which requires their knowledge and a special device, which can simulate this stress condition. At present, the optical method of stress analysis known as photoelasticity is considered as the most lucrative for investigating in detail the stressed state in a granular material. In 1957, Dantu [7] first observed that transmission of force in a packed particle assembly (granular material) can be visualized by photoelasticity. However, in contrast to elastic materials, where stress distribution is directly visualized by sharp isoclines and isolines, a pattern of clear stripes could be observed, which were assumed to represent the major principal stress trajectories. In 1969, de Jong et al. [8] simulated a two-dimensional assembly of a granular material by tests with cylindrical disks of photoelastic material and quantitatively assessed the magnitude and direction of contact forces between the disks by isochromatics, i.e., and equidistant fringe series. In 1972, Drescher and de Jong [9] also adopted this method for investigating aspects of a mathematical model for the flow of a granular material and proposed to transform the distribution of the discrete contact forces and displacements into a second-rank tensor, which provided a satisfactory description of the observed photoelasic phenomenon.

Excellent photoelasic properties of polycarbonate render its wide application to the above research direction of granular mechanical properties. However, the residual stresses generated during polycarbonate injecting and forming processes will strongly reduce the accuracy of the photoelastic experimental results $[10,11]$. The other hindrance to its wider use in granular mechanics is the lack of technologies for producing small-size and high transparent photoelastic particles, which are similar to the small-size granular materials.

In this study, a method of producing millimeter scale $(\geq 1 \mathrm{~mm})$ photoelastic particles and the corresponding annealing regimes relieving the residual stresses are proposed based on numerous trial-and-error experimental tests on small-diameter photoelastic disks produced from polycarbonate plate. The effect of mechanical processing and annealing treatments on mechanical and optical properties, as well as internal pores in the PCM, was also analyzed, which seems to be quite instrumental for further research efforts.

1. PCM Processing Procedure. The raw material and equipment used were polycarbonate plate and an NC (numerical control) plastic engraving machine (Mitsubishi Co., Japan), respectively.

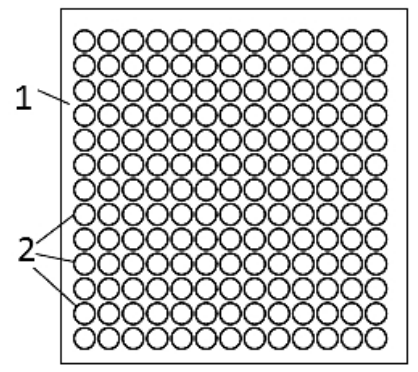

Fig. 1. Schematic drawing of polycarbonate plate NC processing.

The proposed plate-processing procedure is sketched in Fig. 1, where PCM plate (1) is mounted on the processing platform of $\mathrm{NC}$ plastic engraving machine, and multiple small-diameter disks (2) are cut from it with a rotating knife. In this study, the PCM plate thickness was $5 \mathrm{~mm}$ (other options were also tested, but omitted for brevity); a particle processing layout was drawn on the computer according to the diameter of the particle and the PCM plate. A rotating knife was placed on the PCM plate, and the spindle speed was adjusted to $24,000 \mathrm{rpm}$ and a travel speed of $100 \mathrm{~mm} / \mathrm{min}$; then, the machine was turned on to cut the plate according to the layout drawing design. Since in photoelastic tests the light 
direction coincides with the PCM plate normal direction (which runs parallel to cutting plane), the rough and opaque cylindrical surfaces produced by cutting do not affect the light transmission. Thus, small-sized and high-transparent photoelastic disks simulating granular particles can be obtained with no polishing required.

2. PCM Annealing Procedure. During the injection molding process of polycarbonate products, thermal residual stresses are generated, due heterogeneous material flow, consolidation stresess, and temperature fluctuations. Furthermore, mechanical processing of the material induces the residual stresses [11], which affect the PCM optical properties. Those, in turn, strongly affect the final product internal stresses and, accordingly, the accuracy of strain measurements via photoelasticity is deteriorated. The above problem of polycarbonate applicability to photoelastic experiments can be resolved by proper evaluation, reduction or relief of the product residual stresses [12-15], the simplest and the most effective stress-relieving method being the annealing treatment $[16,17]$.

As a mature post-treatment process, annealing is widely applied to improvement of polymer product mechanical properties, including stable tensile strength, high-accuracy dimensions, and good corrosion resistance [18]. The annealing process can be reduced to placing the product into a heating medium and then heating it slowly from room temperature to a certain temperature, which is maintained for a given holding period; finally, the temperature is gradually decreased to room temperature. During the holding periods at thermosol temperature, irregular molecular polymer chains become re-aligned. As the material is viscoelastic, relaxation of the internal stresses allows one to reduce or fully eliminate the residual stresses [15]. The heating process can be realized in different media, such as air, water, oil, etc. By the results of trial-and-error annealing tests in air and oil, air was selected as the optimal annealing medium for this study.

In general, there is no universal annealing procedure, and the "tailor-made" solution has to be experimentally determined according to the shape and size of the product. During the annealing process, the temperature is slowly increased by $10^{\circ} \mathrm{C}$-increments $\mathrm{C}$ with further holding of this temperature for $1 \mathrm{~h}$, in order to provide its homogenous distribution in each part of the product.

3. Annealing Test Results and Discussion. The optimal annealing curves for the cylindrical disks of the same height $(5 \mathrm{~mm})$ and different diameters in the ranges from 1 to $3 \mathrm{~mm}$ and from 4 to $8 \mathrm{~mm}$ are shown in Fig. 2a and 2b, respectively.

In the above annealing tests, heat treatment temperature and time were considered to be the key parameters controlling the annealing effect, which was proven by the respective annealing curves. However, beyond heat treatment and time, it has been found that the distance between the product and the heat source is also of prime importance. The distance was set as 10,20 , and $30 \mathrm{~cm}$, and the product was put into a resistance furnace to anneal according to the same annealing curve. The experimental results indicate that as the distance decreases, the annealing effect becomes more obvious. Finally, it was found that when the distance is too small, the heat treatment temperature and time need to be properly decreased; otherwise, possible deformation and tiny bubbles could be produced in the product. Vice versa, when the distance is too large, the heat treatment temperature and time need to be properly increased; otherwise, high residual stress will be generated in the product.

The comparative analysis of the above annealing conditions implies that the above phenomena can be attributed to the thermal radiation effect, which is frequently neglected in the annealing process planning. There are three heat transfer routes: thermal conduction, thermal convection, and thermal radiation. In order to relieve residual stress by increasing the polycarbonates temperature to the thermal deformation one, heat is usually considered to transfer to the polycarbonate surface by thermal conduction and thermal convection in the heat treatment medium and then to the bulk material by thermal conduction until the product internal and external temperatures are homogenous. However, heat can also be 


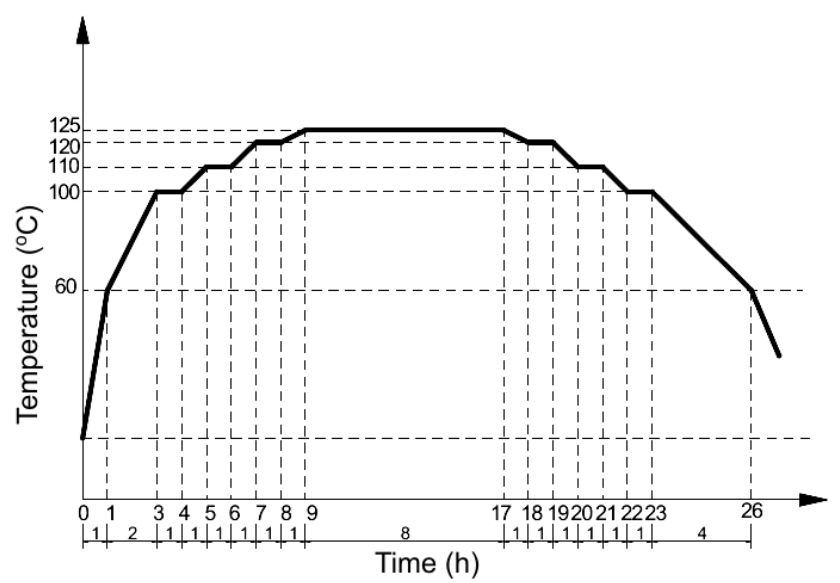

a

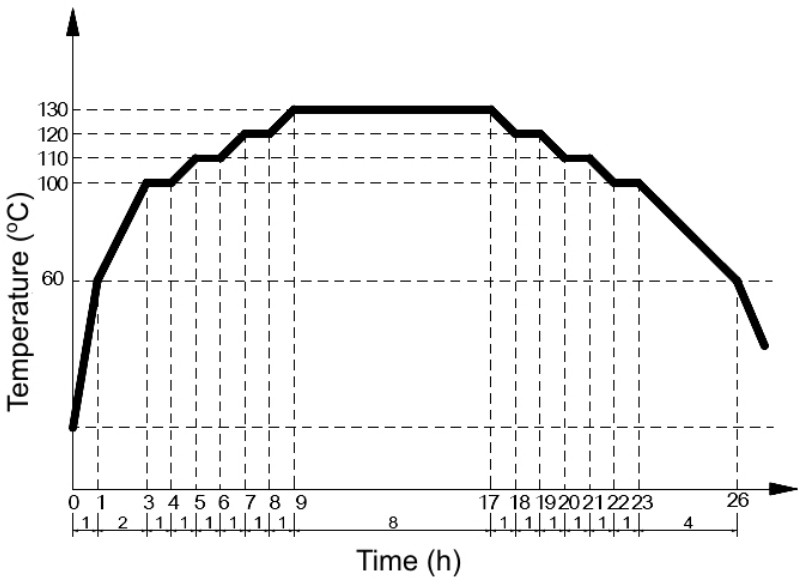

b

Fig. 2. Annealing curves for disks of different diameters: 1 to $3 \mathrm{~mm}$ (a) and 4 to $8 \mathrm{~mm}$ (b).

transferred to the bulk material by thermal radiation. Moreover, polycarbonate is not a good heat conductor, resulting in a more pronounced thermal radiation effect, which explains different annealing effect at different distances. Consequently, it is important to account for thermal radiation in the construction of annealing treatment curves.

4. Experimental Assessment of PCM Photoelastic Properties. Polycarbonate is a good photoelastic plastic material due to its temporary birefringence property [19]. This means that there is no birefringence phenomenon when it is stress-free, but as soon as stresses appear, they give rise to the birefringence effect; however when the stress is relieved, the birefringence phenomenon also disappears. The birefringence property of polycarbonates can be attributed to group or chain orientations of polymers, as well as to the molecular orientation and structure. The intrinsic and stress-induced birefringence occurs due to molecular chain orientation, which is induced by inhomogeneous stresses generated during the injection molding and cooling processes.

As the annealing process has a certain effect on the molecular structure of polycarbonate and residual stresses, it is necessary to study the birefringence effect before and after annealing. In our experiment, the material fringe value $f_{\sigma}$ is used as main criterion of PCM photoelastic properties. 
As seen from the formula for the material fringe value $f_{\sigma}=\lambda / c$, the parameter $f_{\sigma}$ depends on the stress, constant of light $c$, and light source wavelength $\lambda$; however, it is not related to the model shape, size, and loading conditions. Additionally, $f_{\sigma}$ can also be experimentally assessed from the radial compression test of PCM disk (Fig. 3) and its visualization via the photoelasticity technique (Fig. 4).

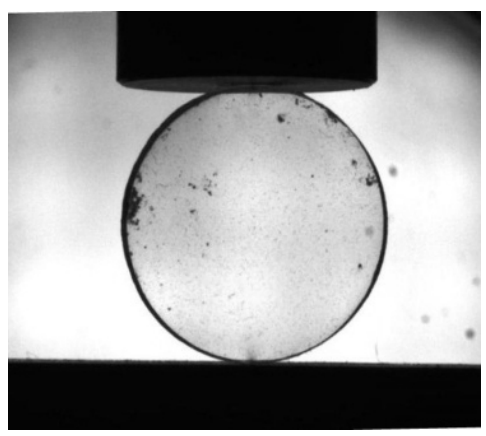

Fig. 3

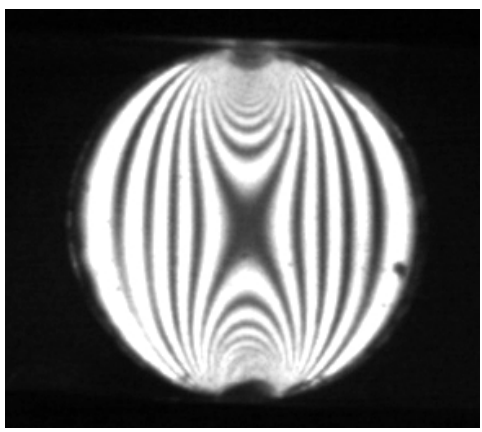

Fig. 4

Fig. 3. Scheme of PCM disk radial compression in photoelastic test.

Fig. 4. The obtained fringes (isochromes and isolines) describing equistress lines in the radially compressed PCM disk.

The theoretical solutions for the major stresses at the center point of the radially compressed disk are:

$$
\begin{gathered}
\sigma_{1}=\frac{2 P}{\pi d D}, \quad \sigma_{2}=-\frac{6 P}{\pi d D}, \\
\sigma_{1}-\sigma_{2}=\frac{n f_{\sigma}}{d} \Rightarrow f_{\sigma}=\frac{8 P}{n \pi d},
\end{gathered}
$$

where $P$ is the load, $D$ is the disk diameter, and $d$ is its thickness.

A monochromatic light source was used in this test with a red light of $631 \mathrm{~nm}$ wavelength. Different fringe grades were produced at the center of the disk by adjusting the load $P$, where the fringe grades $n$ at the disk center point were measured by the Tardy compensation method after 15 min of static load $P$ holding.

5. Photoelastic Test Results and Discussion. As seen from the material fringe value vs. fringe order curves constructed before and after annealing and depicted in Figs. 5 and 6 , the fringe values are variable. The literature survey implies that the fringe value varies with temperature, and it was also determined that the fringe value increases slowly as its grade increases.

By comparing the variation curves obtained before and after annealing in Figs. 5 and 6, it was also established that: (i) after annealing, the variation range of fringe values decreases, and its trend exhibits a saturation; (ii) the fringe value increases as the disk diameter decreases when the fringe grade is the same before annealing, whereas the fringe variation curves of the three different disk diameters almost coincide, indicating that they are invariable of the disk diameter.

The above findings can be substantiated by the following considerations; Irregular molecular chains tangling together in a polycarbonate are re-aligned by annealing, which implies a change in the molecular orientation resulting from the molecular structure (that is, intrinsic birefringence) variation. Meantime, the original stress is relaxed, which in turn decreases the stress birefringence effect induced by the molecular chain orientation resulting from inhomogeneous stresses. 


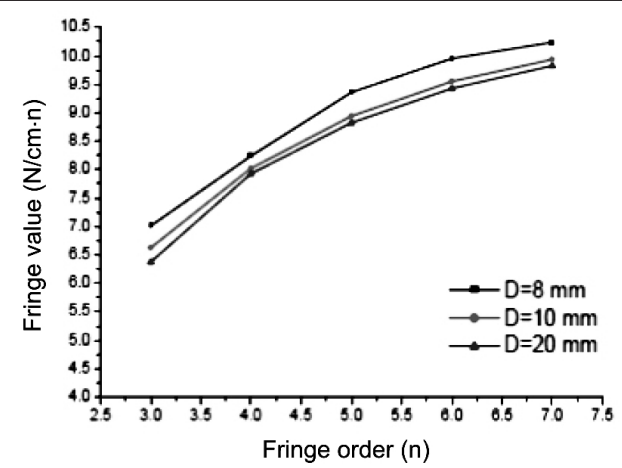

a

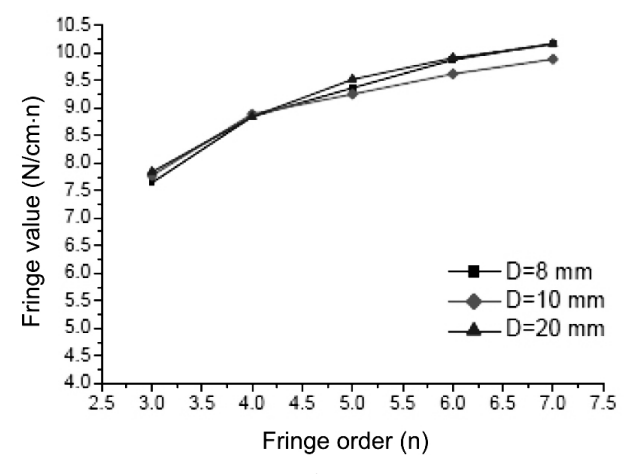

b

Fig. 5. Experimental fringe value vs. fringe order dependences for PCM disks of 8, 10 and $20 \mathrm{~mm}$ in diameter before (a) and after (b) annealing.

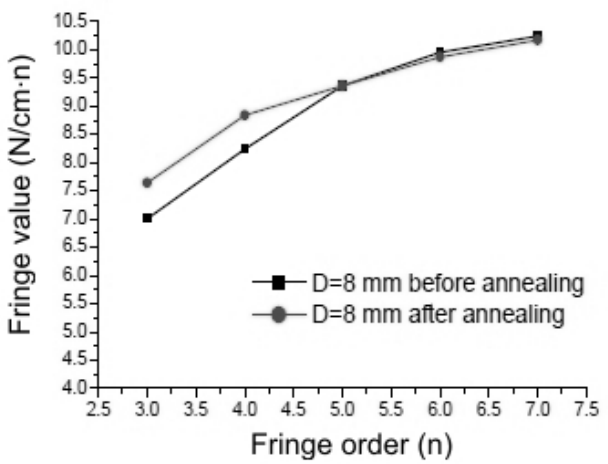

a

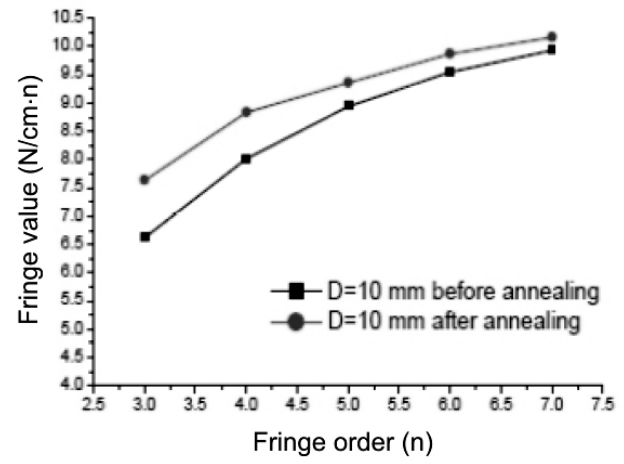

b

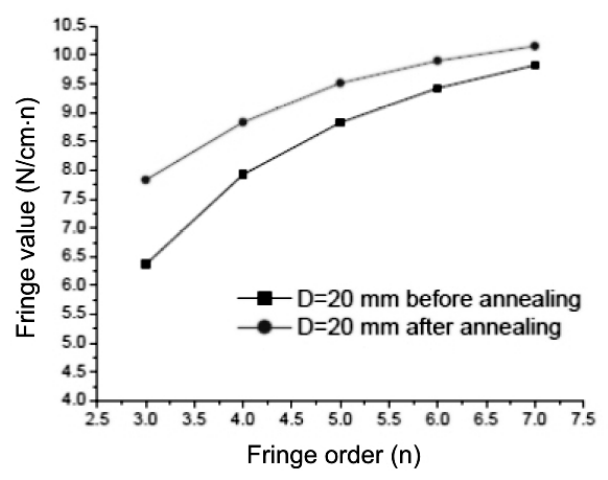

c

Fig. 6. Experimental fringe value vs. fringe order dependences before and after annealing for PCM disks of 8 (a), 10 (b) and $20 \mathrm{~mm}$ (c) in diameter.

Comparing the fringe value variations in disks of different diameters $(8,10$, and $20 \mathrm{~mm})$ before and after annealing (Fig. 6), when the fringe order $n$ is equal to 3, the fringe value of the $8 \mathrm{~mm}$-diameter disk increases from 7 to $7.7 \mathrm{~N} / \mathrm{cm} \cdot n$ (i.e., is increased by $10 \%$ ), while those of 10 and $20 \mathrm{~mm}$-diameter disks exhibit an increase by 16.7 and $20.6 \%$, respectively. This implies that the material fringe value variation and after annealing exhibits higher variation with disk diameter. Therefore, an increase in the disk diameter results in a more pronounced residual stress effect on the material fringe value. 
When the fringe order is equal to 7 , the fringe value of the $8 \mathrm{~mm}$-diameter disk particle decreases from 10.2 to $10.1 \mathrm{~N} / \mathrm{cm} \cdot n$ (and, thus, is reduced by $1 \%$ ), whereas those of the 10 and $20 \mathrm{~mm}$-diameter disks exhibit an increase from 9.6 to $10.0 \mathrm{~N} / \mathrm{cm} \cdot n$ (an increase by $4.2 \%$ ) and from 9.5 to $10.2 \mathrm{~N} / \mathrm{cm} \cdot n$ (an increase by $7.4 \%$ ), respectively. Thus, an increase in fringe order results in smaller variations of the material fringe values after annealing. This means that when the material is subjected to higher loads, resulting in higher fringe orders, the residual stress effect on the material fringe values is less pronounced.

\section{Conclusions}

1. Photoelastic PCM material disks of a small diameter and precise dimensions were successfully produced by a NC plastic engraving machine. Moreover, as the cut plane is parallel to the light, it does not affect the light propagation, thereby ensuring the disk transparency and the accuracy of the photoelastic test.

2. In the PCM annealing treatment, recommended for the residual stress relief, it is necessary to consider thermal radiation factor. Consequently, the distance between the heat source and the material has to be taken into account together with the heat treatment temperature and the holding time determination of annealing regimes. Hence, for the annealing treatment of PCM plates, multiple preliminary tests are needed to determine proper annealing curve and distance.

3. As the disk particle size increases, the effect of residual stress on the material fringe value becomes more pronounced, and as the fringe grade increases, the material fringe values before and after annealing vary only slightly. Moreover, the variation range of the material fringe value is narrowed by the annealing, and its trend attains a saturated pattern. The variation range of the PCM fringe values of a polycarbonate decreases with the fringe order after annealing, which may strongly reduce the fringe value error resulting from the size effect.

Acknowledgments. This material is based upon work supported by the National Natural Science Foundation of China (Grant Nos. 51678171 and 51608139), Science and Technology Planning Project of Guangdong Province (2015B020238014).

\section{Резюме}

Полікарбонат $є$ оптимальним фотопружним матеріалом для проведення механічних випробувань методом фотопружності. Для отримання невеликих частинок полікарбонату, що використовуються при фотопружних випробуваннях гранульованого матеріалу, з полікарбонатної пластини, яку попереднью піддавали відпалу для релаксації залишкових напружень, вирізали прозорі циліндричні диски малого діаметра. Режими різання і відпалу оптимізовано в результаті аналізу механічних і фотопружних властивостей полікарбонатних дисків різного діаметра і постійної висоти (5 мм). Аналіз фотопружних характеристик напружено-деформованого стану дисків і ізохром підтвердив високу ефективність запропонованих режимів обробки і відпалу для даного матеріалу.

1. Y. J. Mergler, R. V. Kampen, and W. J. Nauta, "Influence of yield strength and toughness on friction and wear of polycarbonate," Wear, 258, No. 5, 915-923 (2005).

2. Yang Y., "Optimization of injection-molding process for mechanical and tribological properties of short glass fiber and polytetrafluoroethylene reinforced polycarbonate composites with grey relational analysis," Polym.-Plast. Technol., 45, No. 7, 769-777 (2006).

3. Z.-X. Lu and H. Zhang, "Tensile mechanical properties and failure mechanism of microcellular polycarbonate," China Plastics, 17, No. 01, 41-45 (2003). 
4. Z.-X .Hou, X.-D. Xia, and Z.-R. Wang, "Experimental study on polycarbonate bulge-forming process parameters," J. Harbin Inst. Technol., 36, No. 02, 202-204 (2004).

5. Q.-X. Zhang, Q. Li, and G. Zhang, "Effect of annealing on mechanical and dynamic mechanical properties of polycarbonate injection molding product," CIESC J., 63, No. 06, 1929-1933 (2012).

6. N. Li, X.-L. Zhang, and Q. Zhang, "Study on extrude plate technology and property of polycarbonate," China Plastics Industry, 39, No. 08, 69-72 (2011).

7. P. Dantu, "A contribution to the mechanical and geometrical study of non-cohesive masses," in: Proc. of the 4th Int. Conf. on Soil Mechanics and Foundation Engineering, Vol. 1 (1957), pp. 144-157.

8. G. D. J. de Jong, "Étude photo-élastique d'un empilement de disques," in: R. J. Schotting, H. C. J. van Duijn, and A. Verruijt (Eds.), Soil Mechanics and Transport in Porous Media. Theory and Applications of Transport in Porous Media, Vol. 19, Springer, Dordrecht (2006), pp. 148-161.

9. A. Drescher A. and G. D. J. de Jong, "Photoelastic verification of a mechanical model for the flow of a granular material," in: R. J. Schotting, H. C. J. van Duijn, and A. Verruijt (Eds.), Soil Mechanics and Transport in Porous Media. Theory and Applications of Transport in Porous Media, Vol. 19, Springer, Dordrecht (2006), pp. 28-43.

10. J. Greener, R. Kesel, and B. A. Contestable, "The birefringence problem in optical disk substrates: a modeling approach,” AlChE J., 35, No. 3, 449-458 (1989).

11. W. C. Bushko and V. K. Stokes, "Solidification of thermoviscoelastic melts. Part II: Effects of processing conditions on shrinkage and residual stresses," Polym. Eng. Sci., 35, No. 4, 365-383 (1995).

12. C. H. Kim, S. Kim, and H. Oh, "Measurement of residual stresses in injection molded polymeric part by applying layer-removal and incremental hole-drilling methods," Fiber. Polym., 8, No. 4, 443-446 (2007).

13. S. S. Yang and T. H. Kwon, "A study of birefringence, residual stress and final shrinkage for precision injection molded parts," Korea-Aust. Rheol. J., 19, No. 4, 191-199 (2007).

14. Y. Peng, H. Li, and L. S. Turng, "Development of a rheo-dielectric sensor for online shear stress measurement during the injection molding process," Polym. Eng. Sci., 50, No. 1, 61-68 (2010).

15. X. Wang, Y. Y. Peng, and H.-M. Li, "Effects of annealing on mechanical properties of injection mold polycarbonate parts," CIESC J., 61, No. 06, 1555-1559 (2010).

16. S. Song, J. Feng, and P. Wu, "Annealing of melt-crystallized polyethylene and its influence on microstructure and mechanical properties, A comparative study on branched and linear polyethylenes," J. Polym. Sci. Part B, Polym. Phys., 49, No. 19, 1347-1359 (2011).

17. I. Karacan and H. Benli, "The influence of annealing treatment on the molecular structure and the mechanical properties of isotactic polypropylene fibers," J. Appl. Polym. Sci., 122, No. 5, 3322-3338 (2011).

18. C. S. Lee, R. M. Caddell, and A. G. Atkins, "Heat treatment of cold extruded polycarbonate, some implications for design engineers," Mater. Sci. Eng., 18, No. 2, 213-220 (1975).

19. F. Q. Guo, X. J. Fu, and F.-C. Xie, "Current Situation of application and recycling utilization technologies of optical polycarbonate," Chem. Propell. Polym. Mater., 6, No. 04, 11-15 (2008). 